\title{
The influence of age on memory for distinctive events
}

\author{
Lisa GeraCi \\ Texas A\&M University, College Station, Texas \\ MARK A. MCDANIEL \\ Washington University, St. Louis, Missouri \\ Isabel Manzano \\ Texas A\&M University, College Station, Texas
}

AND

HeNRY L. Roediger III

Washington University, St. Louis, Missouri

\begin{abstract}
We examined whether memory for distinctive events is influenced by aging. To do so, we used a semantic isolation paradigm in which people show superior memory for a word when it is presented in a list of items from a different semantic category (e.g., the word table is presented in a list of all bird exemplars) as compared with when the same word (table) is presented in a list of unrelated words. Results showed that both younger and older adults demonstrated an isolation effect in memory, although older adults showed a numerically smaller isolation effect than did younger adults. Results suggest that in contrast with previous findings (Cimbalo \& Brink, 1982), older adults can take advantage of this type of distinctiveness to aid memory performance.
\end{abstract}

Numerous studies with younger adults demonstrate the importance of processing an item's distinctive properties for later memory performance (see Hunt \& Worthen, 2006; Schmidt, 1991, for reviews). However, there is very little research examining whether distinctiveness also aids memory performance for older adults, and the few published studies on the topic are mixed. The experiment reported in the present article explored the effect of aging on memory for distinctive information using a classic semantic isolation paradigm.

\section{The Isolation Effect}

The isolation effect - sometimes called the von Restorff effect (von Restorff, 1933) — may be the most well-known distinctiveness effect reported in the literature. It refers to the finding that people typically show superior memory for unusual or incongruent items (see Hunt, 1995, for details of von Restorff's original study). In the isolation paradigm, participants study a list of items in which one item is different along some dimension from the remainder of the list items. An item can be isolated because it is physically different from the other list items. For example, people show superior memory performance for items that are printed in either a larger font or a different color from the other items in the study list (see, e.g., Kelley \& Nairne, 2001; Kishiyama \& Yonelinas, 2003; Rundus, 1971), as well as for items that are encased in brackets within a list of words without brackets (e.g., McLaughlin, 1968; see also Wallace, 1965, for a review). In these instances, the item is isolated from the other items in the study list via some physical manipulation.

An item can also be semantically isolated at study. For example, people show superior memory performance for items that are from a different semantic category than other items in the study list that are all from the same category (e.g., the word cow, presented in a list of furniture exemplars, such as couch, dresser, table, bookcase; Geraci \& Rajaram, 2004; Hunt \& Lamb, 2001; Schmidt, 1985). Memory for the word cow in this context is typically compared with that for the word cow when it is not isolated at study - for example, presented either in a heterogeneous list of categorically unrelated words or in a homogeneous list of items from the same category (e.g., four-footed animals; see Hunt, 2006, for a discussion of various types of control lists). The typical finding is that people show superior recall of the item when it is isolated at study in comparison with when it is not.

\section{Aging and the Isolation Effect}

One early study showed that older adults did not demonstrate an isolation effect in short-term memory using a physical isolation paradigm (Cimbalo \& Brink, 1982). 
Participants studied 12 lists of consonants. In half of the lists, one consonant in the list was presented in a larger font than the remainder of the consonants, whereas the other half of the lists contained consonants that were all printed in the same, smaller font size. Immediately following the intentional study of each list, participants were instructed to recall the consonants in their order of occurrence. Results showed that younger adults demonstrated an isolation effect; they showed superior serial position recall of the isolated consonants as compared with the nonisolated consonants. By contrast, older adults did not show this isolation effect, supporting the tentative claim that the isolation effect is reduced or absent in older adults.

Some methodological aspects of Cimbalo and Brink's (1982) study may limit the generalizability of their finding, however. For example, the Cimbalo and Brink study used a subtle perceptual font-size manipulation (the isolate was larger than the remaining list items by only $1 \mathrm{~mm}$ ), so it is not clear whether the lack of an isolation effect for older adults was due to a deficient memory process or a deficient perceptual process (such as an inability to sufficiently detect font-size changes). In addition, the use of a control list containing only items of the same font precludes counterbalancing of the target item. A target letter presented in a large font (in the isolation list) may not be equivalent to a different letter presented in a smaller font (in the nonisolated list; see Hunt, 1995, for a discussion of appropriate control lists). Also, the demand to recall the items in the order of presentation may have contributed to the disappearance of the isolation effect in older adults. Lastly, intentional study may have conferred an advantage for younger adults because older adults have been shown to use less effective encoding strategies than younger adults do (Craik \& Rabinowitz, 1984).

Thus, it is not clear whether older adults failed to demonstrate an isolation effect in short-term memory because they had difficulties detecting font-size changes, remembering order information, engaging in effective encoding strategies, or processing distinctiveness specifically. Further complicating the picture, using the same font manipulations as Cimbalo and Brink (1982), an isolation effect was found by Vitali et al. (2006) for older adults in immediate recall (see also Bireta, Surprenant, \& Neath, 2008). Accordingly, the question remains whether older adults will demonstrate a distinctiveness effect when long-term memory is tested using a semantic isolation paradigm with incidental encoding instructions. Furthermore, will older adults demonstrate an isolation effect advantage using a conceptual rather than a perceptual font manipulation? The goal of the present study was to answer these questions.

\section{Aging and Memory for Distinctive Events}

The pattern of data from the few aging and isolation studies is mixed, but related work suggests that the processes associated with the encoding and retrieval of distinctive information may be affected by aging. In particular, older adults generally have difficulty engaging in attentionally demanding processes (see Balota, Dolan, \& Duchek, 2000, for review), which may lead them to have difficulty encoding distinctive events. Traditional attention accounts of the isolation effect propose that the isolate itself attracts attention the moment it is encountered, often due to the surprising nature of the event (see, e.g., Green, 1956; Jenkins \& Postman, 1948; see McDaniel \& Geraci, 2006, for review of these theories). These theories have not fared well because they have difficulty explaining isolation effects that occur for items that are placed at the beginning of a list (e.g., Bone \& Goulet, 1968; Kelley \& Nairne, 2001) before there is anything surprising or notable about the item. In contrast, we have proposed elsewhere that distinctiveness effects arise from attention-demanding processing that involves evaluating and comparing the different items to an established norm over the course of the encoding episode (Geraci \& Rajaram, 2002, 2004, 2006; see also Geraci \& Manzano, in press). According to this view, people evaluate items as being different from the standard that is provided by the study list or by one's own general knowledge. This standard is sometimes established by the time one encounters the odd item in cases in which the item is odd with respect to general knowledge, as in the case of orthographically distinct words or bizarre sentences, or when an isolated item appears later in the study list. Other times the standard is established during the encoding episode, but shortly after the isolate is encountered (as is the case when an isolated item appears early in the study list). In both cases, this view suggests that people evaluate the item as distinctive once the background context has been established (Geraci \& Manzano, in press) and that this process requires some amount of attention (Geraci \& Rajaram, 2002). Because older adults have reduced attentional abilities required for this type of evaluative processing (relative to younger adults), one might predict that they would have difficulty encoding the distinctive item.

In addition to possible difficulties at encoding, some older adults may not demonstrate an isolation effect in memory because of problems retrieving the isolated item. Research shows that for the isolation effect to emerge, the study context must be reinstated at test, and often participants must consciously recollect the context for effects to occur (Hunt \& Smith, 1996; Smith \& Hunt, 2000). Because older adults have declines in conscious recollection (see Fleischman \& Gabrieli, 1998; La Voie \& Light, 1994; Light, Prull, La Voie, \& Healy, 2000, for reviews; see also Hay \& Jacoby, 1999), they may have difficulty retrieving isolated items. Indeed, evidence from other paradigms indicates that older adults may have difficulty retrieving distinctive information. For example, the low-frequency recognition benefit for hits declines steadily with age and is eliminated by dementia of the Alzheimer's type (Balota, Burgess, Cortese, $\&$ Adams, 2002). Thus, older adults may not demonstrate an isolation effect in memory because of difficulties either in using the study context to evaluate the isolated item as distinctive or in retrieving the isolated item (or both).

Together, the aforementioned theoretical considerations suggest that older adults may not benefit from distinctiveness in the isolation paradigm to the same extent as do younger adults. The empirical data are mixed, however, and there are other types of distinctiveness effects that older adults do demonstrate (see, e.g., Mäntylä \& Bäckman, 1992; see also Smith, 2006, for review). Therefore, 
the goal of the present study is to examine whether older adults show an isolation effect in long-term memory using a semantic isolation paradigm. Younger and older adults studied categorized lists containing an item from a different category, as well as several categorically heterogeneous lists containing control items; then, they took a final category cued recall test. Because we were ultimately interested in whether older adults would spontaneously encode distinctive information in a manner similar to that of younger adults, participants were given incidental study instructions. We note that some types of physical isolation effects have not been obtained using incidental study instructions (see Wallace, 1965, for review of this issue), but incidental study tasks may reduce the effect in some cases, because the orienting tasks require processes that override the processes associated with isolation (see Hunt \& Lamb [2001] for an example of how an incidental study orienting task increases memory performance for background items). In the present study, participants were simply required to read the words - an orienting task that was disguised as a reading time task. When young participants are asked to read the study words, the isolation effect is obtained using the current semantic isolation paradigm (Geraci \& Rajaram, 2004). Other distinctiveness effects, including the orthographic distinctiveness effect, are also obtained using an incidental reading task (Geraci \& Rajaram, 2002).

\section{METHOD}

\section{Participants}

Forty Texas A\&M University undergraduate students $(M$ age $=$ 18.55 years) participated for research credit, and 40 older adults ( $M$ age $=73.85$ years) from the local community participated and received a small honorarium for their time. Education level was higher for older adults $(M=16.10, S D=2.90)$ than for younger adults $(M=12.55, S D=.64)\left[F(1,78)=57.20, M S_{\mathrm{e}}=4.36\right]$. Older adults were given a Mini Mental State exam (MMSE; Folstein, Folstein, \& McHugh, 1975) according to standard procedures. The average MMSE score was $28.75(S D=1.24)$. Lastly, all participants filled out a demographic questionnaire that included several health questions. None of the younger or older adults included in this sample reported any history of stroke, other neurological disorders, brain injury, or serious cardiovascular conditions.

\section{Design}

The experiment used a $2 \times 2$ mixed factorial design. Age group (younger and older adults) served as the between-subjects variable, and item type (isolated and nonisolated) served as the withinsubjects variable.

\section{Materials}

The following paradigm was taken from Geraci and Rajaram (2004). Twenty-four categorized lists of eight words each were derived from the Battig and Montague (1969) and Shapiro and Palermo (1970) category norms. All items were chosen from among the 10 most common exemplars for each category. For each list, one of the eight items served as the critical item.

Six of the 12 study lists were structured so that the critical item was distinct because it was the only item from its category presented in the list. For example, the word table was presented in a list of types of fish (e.g., trout, herring, shark, catfish, table, perch, salmon, tuna). The other 6 lists were structured so that the critical item table was not isolated. In these lists, all the words including the critical item were from different semantic categories (e.g., opium, cookies, sponge, salmon, inch, table, spokes, four). In all lists, the critical item appeared in the fifth, sixth, or seventh serial position. Across participants, the same critical item served as either an isolated or a nonisolated item by virtue of the study list structure, or as a nonstudied item. Counterbalancing across item type (isolated and nonisolated) and study status (studied and nonstudied) produced four study list versions. Participants were presented with all 12 lists in a semirandomized order, with the condition that no more than 2 isolated or nonisolated lists appeared in a row. The test list consisted of 24 category cues, half of which corresponded to studied items (isolated and nonisolated) and half of which corresponded to nonstudied items.

\section{Procedure}

During list presentation, each word was seen on the computer screen for $3 \mathrm{sec}$. As was mentioned, an incidental study task was used to examine whether participants would spontaneously encode the isolated items differently from the nonisolated items. Younger and older adult participants were told that the purpose of the experiment was to measure reading time, and they were asked to read each word silently and to press the space bar as soon as they had finished reading the word. They were led to believe that the space bar press recorded their reading times. Participants were instructed to focus on the word until the screen advanced to the next item, even after they pressed the space bar. They were told that they needed to focus on the word the entire time so that they would not miss the onset of the next word. The 12 study lists were each separated by a 5 -sec break during which participants waited for the next list. After $5 \mathrm{sec}$, the screen advanced and participants saw another screen that indicated that the next list was imminent. Participants were instructed to prepare for the next list by placing their dominant hand over the space bar. After the study phase, participants were given a 5-min visual distractor task in which they were asked to rank four interior angles from smallest to largest.

At test, participants were given a category cued recall test. They were given test packets that included 24 category labels (e.g., a piece of furniture) and were asked to try to recall a word they saw earlier from the given category. Twelve category labels corresponded to the critical studied items ( 6 of which had been isolated at study and 6 that had not been isolated at study), and 12 category labels corresponded to nonstudied items. For each label, participants were given $30 \mathrm{sec}$ to try to recall an item from that category that they had studied. They were told that if they could not recall an item or were sure that they had not studied an item from the category presented, then they should leave the answer sheet blank. After the cued recall task, all participants were asked to describe what they had noticed about the structure of the lists they had seen earlier during the "reading time" test. We coded whether participants spontaneously mentioned the fact that some of the lists contained isolated items.

\section{RESULTS}

Results of statistical tests were significant at $p<.05$. $F$ values, $M S_{\mathrm{e}} \mathrm{s}$, and effect sizes $\left(\eta_{\mathrm{p}}^{2}\right)$ were included for each analysis. Mean recall of isolated, nonisolated, and nonstudied items is presented at the top of Table 1. Be-

Table 1

Mean Proportions and Standard Deviations of Isolated, Nonisolated, and Nonstudied Items Recalled for Younger Adults and Older Adults Age

\begin{tabular}{cccccc}
\hline & \multicolumn{4}{c}{ Age } \\
\cline { 2 - 3 } \cline { 5 - 6 } \multicolumn{1}{c}{ Item } & \multicolumn{2}{c}{ Younger } & & \multicolumn{2}{c}{ Older } \\
\cline { 2 - 3 } \cline { 5 - 6 } & $M$ & $S D$ & & $M$ & $S D$ \\
\hline Isolated & .35 & .25 & & .28 & .20 \\
Nonisolated & .22 & .17 & & .21 & .18 \\
Nonstudied & .04 & .08 & & .02 & .05 \\
\hline
\end{tabular}


cause false alarms to critical nonstudied items were very low and did not significantly differ across groups, all analyses were conducted on hits to studied items. In order to examine the influence of age on memory for isolated and nonisolated items, we conducted a 2 (younger, older) $\times 2$ (isolated, nonisolated) ANOVA. Results from this analysis showed that there was a main effect of item type $[F(1,78)=$ 9.04, $\left.M S_{\mathrm{e}}=.04, \eta_{\mathrm{p}}^{2}=.10\right]$, showing that participants recalled more isolated than nonisolated items $(M \mathrm{~s}=.32$ and $.22)$, but no main effect of age $\left[F(1,78)=1.47, M S_{\mathrm{e}}=\right.$ $\left..04, \eta_{\mathrm{p}}^{2}=.02\right]($ older $=.25$ and younger $=.29)$, and no interaction between the two variables $[F(1,78)=1.39$, $\left.M S_{\mathrm{e}}=.04, \eta_{\mathrm{p}}^{2}=.02\right] .{ }^{1}$

For completeness, we also examined the number of blanks and false recall of noncritical items for the three types of cues: isolated, nonisolated, and nonstudied. Results showed no age differences between the number of blanks for common items ( $M=.57$ for both groups) or nonstudied items ( $M=.77$ for both groups), but older adults were more likely to leave blanks when recalling a critical item to a category name than were younger adults $[M=.57 \mathrm{vs}$. $\left..44 ; F(1,78)=5.23, M S_{\mathrm{e}}=.07, \eta_{\mathrm{p}}^{2}=.06\right)$. False recall of noncritical items did not differ for younger and older adults (false recall of common items was 20 for both groups, false recall of distinctive items was .20 for younger and .15 for older adults, and false recall of nonstudied items was .23 for younger and .22 for older adults).

As was mentioned earlier, after the cued recall test, younger and older adults were asked to indicate what they had noticed about the study lists. Results showed that all of the older adults indicated that the lists were categorized, and approximately half (23) spontaneously reported noticing that some of the lists contained odd items that did not fit with the category structure of the list (incidentally, the exact same number of younger adults also spontaneously reported noticing the presence of odd items). Thus, it does not appear that the older adults in the present study were more likely to ignore the odd item than were the younger adults. However, awareness was associated with a larger distinctiveness advantage for both younger and older adults. Aware younger adults recalled significantly more isolated than nonisolated items $[M=.38$ vs. $.21 ; t(22)=2.25, S E=.07]$, whereas unaware younger adults did not recall significantly more isolated than nonisolated items $[M=.32$ vs. $.24 ; t(16)=1.12, S E=.11]$. Similarly, aware older adults recalled significantly more isolated than nonisolated items $[M=.33$ vs. .20; $t(22)=$ $2.94, S E=.05]$, whereas unaware older adults did not recall significantly more isolated than nonisolated items $[M=.26$ vs. $.21 ; t(16)<1]$. For both groups, the isolation effect was double the size for the aware participants, but younger and older adults were as likely to report awareness of the isolate, in contrast with the reports from Cimbalo and Brink (1982).

\section{DISCUSSION}

Overall, the younger adult data replicate the results from Geraci and Rajaram (2004, Experiment 2) and are consistent with many other studies showing that younger adults have superior memory for isolated items (e.g., Hunt, 1995; Hunt \& Lamb, 2001; von Restorff, 1933). Our results for older adults are consistent with those from Bireta et al. (2008), who also found that both younger and older adults benefited from isolation. Thus, the isolation effect displayed by older adults in the present experiment generalizes across the differences in methodology and materials from the present study to the study by Bireta et al., as well as to that reported by Vitali et al. (2006). Older adults appear to show superior memory for isolates regardless of whether the isolate is semantically different from the remaining items, as in the present study, or physically different from the remaining items, as in the Bireta et al. and Vitali et al. studies. In addition, the isolation effect appears for younger and older adults regardless of whether a final cued recall test is used, as was the case in the present study, or whether several immediate free recall tests are used, as was the case in the previous two studies (Bireta et al., 2008; Vitali et al., 2006). Finally, the isolation effect occurs for older adults even when incidental study instructions are used, as in the case of the present study.

However, the results from the present experiment are inconsistent with those from the first study on this topic conducted by Cimbalo and Brink (1982), which showed that older adults did not demonstrate a physical isolation effect on a short-term order recall task. Design differences across studies could help explain the disparate results for older adults. The design of the Cimbalo and Brink study differed from that of the three studies (including the present one) just described that show the isolation effect for older adults. Critically, participants in the Cimbalo and Brink study were required to recall the items in correct study order, whereas participants in the present study and in the Bireta et al. (2008) and Vitali et al. (2006) studies could recall the items in any order. Thus, the requirement to recall the items in the correct order may have placed heavy demands on recall and diminished the isolation effect for older adults. In addition, in the Cimbalo and Brink study, the isolate differed only subtly from the other items in the list (it was only larger by $1 \mathrm{~mm}$ ), whereas in the other published studies using physical isolation (Bireta et al., 2008; Vitali et al., 2006), the isolate differed more dramatically from the background items and each item was presented sequentially. Furthermore, the study lists in the Cimbalo and Brink experiment included lists of single consonants, rather than words, which may have been more difficult to distinguish from one another and less meaningful for older adults to remember than words that were presented in the present study and in the Bireta et al. and Vitali et al. studies.

One other finding reported by Cimbalo and Brink (1982) is worth noting. They described the fact that only one older adult in their study spontaneously reported noticing the presence of the isolate. For this reason, the authors argued that older adults may ignore the presence of the isolate. In the present study, older adults were also asked to describe what they noticed about the structure of the lists they had read, but we found that the older 
adults were just as likely as the younger adults to mention the presence of the isolate. The reason for this difference across studies is unclear, but it could be that the semantic isolates are more noticeable or important to older adults than are subtle physical font-size changes; or perhaps some older adults are more likely to notice and report isolated items than are other older adults.

Although there was no evidence for an age $\times$ item type (isolated, nonisolated) interaction in the present study, older adults did show a numerically smaller isolation effect than did younger adults (see also Bireta et al., 2008). It is possible that there is variation among older adults in the extent to which they show superior recall for isolated items. In particular, older adults with worse attentional control abilities may be less likely to show an isolation effect in memory than would those with better attentional control abilities. As was discussed earlier, attentional control may be important for the isolation advantage to occur because this effect may require attention-demanding processes either during encoding (such as evaluating the item as odd once the list context unfolds; Geraci \& Manzano, in press; Geraci \& Rajaram, $2002,2004,2006$ ) or during retrieval (such as consciously recollecting the study context; see McDaniel \& Geraci, 2006, and Smith \& Hunt, 2000). Indeed, results from a recent study showing that older adults with Alzheimer's disease did not show an isolation effect in memory can be taken as support for this view (Vitali et al., 2006). Given that declines in attentional control have been associated with early Alzheimer's disease (e.g., Balota \& Faust, 2001), it is possible that older adults with Alzheimer's disease did not show an isolation effect because of attentional limitations associated with the progression of the disease. Future research should examine the contribution of individual differences in cognitive functioning to older adults' memories for isolated items. For now, though, the present study shows that both younger and older adults can take advantage of distinctiveness when it is created using a semantic isolation paradigm.

\section{AUTHOR NOTE}

Portions of this research were presented at the 2004 Cognitive Aging Conference in Atlanta, Georgia. This research was supported by NIA Grant P50 AG056811, awarded to L.G., and NIA Grant AG17481, awarded to M.M. and H.R. We thank Maryellen Hamilton and Dave McCabe for comments on an earlier draft of the manuscript. Correspondence should be sent to L. Geraci, Department of Psychology, Texas A\&M University, College Station, TX 77843-4235 (e-mail: lgeraci@tamu.edu).

\section{REFERENCES}

Balota, D. A., Burgess, G. C., Cortese, M. J., \& Adams, D. R. (2002). The word-frequency mirror effect in young, old, and early Alzheimer's disease: Evidence for two processes in episodic recognition performance. Journal of Memory \& Language, 46, 199-226.

Balota, D. A., Dolan, P. O., \& DucheK, J. M. (2000). Memory changes in healthy older adults. In E. Tulving \& F. I. M. Craik (Eds.), The Oxford handbook of memory (pp. 395-409). Oxford: Oxford University Press.

Balota, D. A., \& Faust, M. E. (2001). Attention in dementia of the Alzheimer's type. In F. Boller \& S. F. Cappa (Eds.), Handbook of neuropsychology (2nd ed., pp. 51-80). Amsterdam: Elsevier.

Battig, W. F., \& Montague, W. E. (1969). Category norms for verbal items in 56 categories: A replication and extension of the Connecticut category norms. Journal of Experimental Psychology Monograph, 80, $1-46$.

Bireta, T. J., Surprenant, A. M., \& Neath, I. (2008). Age-related differences in the von Restorff isolation effect. Quarterly Journal of Experimental Psychology, 61, 345-352.

Bone, R. N., \& Goulet, L. R. (1968). Serial position and the von Restorff isolation effect. Journal of Experimental Psychology, 76, 494-496.

Cimbalo, R. S., \& Brink, L. (1982). Aging and the von Restorff isolation effect in short/term memory. Journal of General Psychology, 106, 69-76.

Craik, F. I. M., \& Rabinowitz, J. C. (1984). Age differences in the acquisition and use of verbal information: A tutorial review. In H. Bouma \& D. G. Bouwhuis (Eds.), Attention and performance X: Control of language processes (pp. 471-499). Hillsdale, NJ: Erlbaum.

Fleischman, D. A., \& Gabrieli, J. D. E. (1998). Repetition priming in normal aging and Alzheimer's disease: A review of findings and theories. Psychology \& Aging, 13, 88-119.

Folstein, M. F., Folstein, S. E., \& McHugh, P. R. (1975). Mini-mental state: A practical method for grading the cognitive state of patients for the clinician. Journal of Psychiatric Research, 12, 189-198.

Geraci, L., \& Manzano, I. (in press). Distinctive items are salient during encoding: Delayed judgments of learning predict the isolation effect. Quarterly Journal of Experimental Psychology.

Geraci, L., \& RAJARAm, S. (2002). The orthographic distinctiveness effect on direct and indirect tests of memory: Delineating the awareness and processing requirements. Journal of Memory \& Language, 47, 273-291.

Geraci, L., \& RaJARAm, S. (2004). The distinctiveness effect in the absence of conscious recollection: Evidence from conceptual priming. Journal of Memory \& Language, 51, 217-230.

Geraci, L., \& RAJARAM, S. (2006). The distinctiveness effect in explicit and implicit memory. In R. R. Hunt \& J. Worthen (Eds.), Distinctiveness and memory (pp. 211-234). New York: Oxford University Press.

Green, R. T. (1956). Surprise as a factor in the von Restorff effect. Journal of Experimental Psychology, 52, 340-344.

HAY, J. F., \& JACOBY, L. L. (1999). Separating habit from recollection in younger and older adults: effects of elaborative processing and distinctiveness. Psychology \& Aging, 14, 122-134.

Hunt, R. R. (1995). The subtlety of distinctiveness: What von Restorff really did. Psychonomic Bulletin \& Review, 2, 105-112.

HunT, R. R. (2006). The concept of distinctiveness in memory research. In R. R. Hunt \& J. Worthen (Eds.), Distinctiveness and memory (pp. 3-25). Oxford: Oxford University Press.

HunT, R. R., \& LAMB, C. A. (2001). What causes the isolation effect? Journal of Experimental Psychology: Learning, Memory, \& Cognition, 27, 1359-1366.

Hunt, R. R., \& Smith, R. E. (1996). Accessing the particular from the general: The power of distinctiveness in the context of organization. Memory \& Cognition, 24, 217-225.

Hunt, R. R., \& Worthen, J. O. (Eds.) (2006). Distinctiveness and memory. Oxford: Oxford University Press.

Jenkins, W. O., \& Postman, L. (1948). Isolation and "spread of effect" in serial learning. American Journal of Psychology, 61, 214-221.

Kelley, M. R., \& NAIRNE, J. S. (2001). von Restorff revisited: Isolation, generation, and memory for order. Journal of Experimental Psychology: Learning, Memory, \& Cognition, 27, 54-66.

Kishiyama, M. M., \& Yonelinas, A. P. (2003). Novelty effects on recollection and familiarity in recognition memory. Memory \& Cognition, 31, 1045-1051.

LA Voie, D., \& Light, L. L. (1994). Adult age differences in repetition priming: A meta-analysis. Psychology \& Aging, 9, 539-553.

Light, L. L., Prull, M. W., LA Voie, D., \& Healy, M. R. (2000). Dualprocess theories of memory in older age. In T. J. Perfect \& E. A. Maylor (Eds.), Models of cognitive aging (pp. 238-300). Oxford: Oxford University Press.

MÄNTYLÄ, T., \& BÄCKMAN, L. (1992). Aging and memory for expected and unexpected objects in real-world settings. Journal of Experimental Psychology: Learning, Memory, \& Cognition, 18, 1298-1309.

McDaniel, M. A., \& Geraci, L. (2006). Encoding and retrieval processes in distinctiveness effects: Toward an integrative framework. In R. R. Hunt \& J. Worthen (Eds.), Distinctiveness and memory (pp. 6588). Oxford: Oxford University Press. 
McLaughlin, J. P. (1968). Recall and recognition measures of the von Restorff effect in serial learning. Journal of Experimental Psychology, 78, 99-102.

RunDus, D. (1971). Analysis of rehearsal processes in free recall. Journal of Experimental Psychology, 89, 63-77.

SCHMIDT, S. R. (1985). Encoding and retrieval processes in the memory for conceptually distinctive events. Journal of Experimental Psychology: Learning, Memory, \& Cognition, 11, 565-578.

SchmidT, S. R. (1991). Can we have a distinctive theory of memory? Memory \& Cognition, 19, 523-542.

Shapiro, S. I., \& Palermo, D. S. (1970). Conceptual organization and class membership: Normative data for representatives of 100 categories. Psychonomic Monograph Supplements, 3, 221-242.

Smith, R. E. (2006). Adult age differences in episodic memory: Itemspecific, relational, and distinctive processing. In R. R. Hunt \& J. Worthen (Eds.), Distinctiveness and memory (pp. 259-287). Oxford: Oxford University Press.

Smith, R. E., \& Hunt, R. R. (2000). The effects of distinctiveness require reinstatement of organization: The importance of intentional memory instructions. Journal of Memory \& Language, 43, 431-446.

Vitali, P., Minati, L., Chiarenza, G., Brugnolo, A., Girtler, N.,
Nobili, F., ET AL. (2006). The von Restorff effect in aging and Alzheimer's disease. Neurological Sciences, 27,166-172.

vON REstoRFF, H. (1933). Über die Wirkung von Bereichsbildungen im Spurenfeld. Psychologishe Forschung, 18, 299-342.

Wallace, W. P. (1965). Review of the historical, empirical, and theoretical status of the von Restorff phenomenon. Psychological Bulletin, 63, $410-424$.

\section{NOTE}

1. The interaction did not reach significance $(p=.24)$. Power analyses show that with over 200 participants, there would be an $80 \%$ chance of detecting a significant interaction with this size effect. When we included 80 additional participants from an identical condition of another study (for a total of 160 younger and older adults) with the present data, we did not obtain a significant interaction. Thus, we conclude that both younger and older adults benefit from this type of distinctiveness.

(Manuscript received July 25, 2008;

revision accepted for publication October 29, 2008.) 